\title{
The effect of addition of hydroxyapatite from skipjack tuna (katsuwonus pelamis) fish bone flour to the transverse, impact, and tensile strength of heat cured acrylic resin
}

\author{
Diwya N. Hapsari, ${ }^{,}$Sinta C. Wardani, ${ }^{,}$Wahidatul A. Firdausya, \\ Khoulah Amaturrohman, Hepy P. Wiratama
}

\begin{abstract}
Objective: This study aims to determine the effect that occurs when heat cured acrylic resin is added hydroxyapatite which is synthesized from skipjack fish bones.

Material and Methods: This study using 27 samples of heat cured acrylic resin for each mechanical strength divided into 3 groups, namely groups with the addition of $0 \%, 2 \%$, and $5 \%$ hydroxyapatite from the weight of the polymer.

Results: The analysis showed a significant decrease in transverse

test, $p=0.001)$, a significant decrease in impact strength occurred in both groups of $2 \%$ and $5 \%$ addition of hydroxyapatite (One-way Anova test, $p=0.000$ ), and also the addition of $2 \% \& 5 \%$ hydroxyapatite caused a significant decrease in tensile strength (One-way Anova test, $p=0.018$ ).

Conclusions: Hydroxyapatite synthesized from skipjack fish bone affects the mechanical strength of acrylic resins, namely transverse, impact and tensile.
\end{abstract} strength with 5\% addition of hydroxyapatite group (One-way Anova
Department of Prosthodontics, Faculty of Dentistry, Brawijaya University, Malang, Indonesia
*Correspondence to: Diwya N. Hapsari, Sinta C. Wardani, Department of Prosthodontics, Faculty of Dentistry, Brawijaya University, Malang, Indonesia ipehprosto.fk@ub.ac.id; sinta.candra@ub.ac.id

Received: 24 November 2019 Revised: 14 February 2020 Accepted: 1 June 2020 Available Online: 1 August 2020

Keywords: Heat cured acrylic resin, Hydroxyapatite, Impact strength, Skipjack tuna fish bone, Tensile strength, Transverse strength Cite this Article: Hapsari DN, Wardani SC, Firdausya WA, Amaturrohman K, Wiratama HP. 2020. The effect of addition of hydroxyapatite from skipjack tuna (katsuwonus pelamis) fish bone flour to the transverse, impact, and tensile strength of heat cured acrylic resin. Journal of Dentomaxillofacial Science 5(2): 94-97. D01: 10.15562/jdmfs.v5i2.1016

\section{Introduction}

Removable partial denture made from heat cured polymethylmethacrylate (PMMA) resin is one type of denture that is often used. Acrylic resin is used as a base for artificial teeth because this material is non-toxic, non-irritating, good aesthetic, inexpensive, easy to manipulate, easy to repair and has small dimension changes. However, polymethylmethacrylate acrylic resins also have the disadvantage of being easily fractured. These deficiencies often cause problems such as fracture of the denture base due to compressive force in the oral cavity or due to falling. ${ }^{1}$ The denture base made of methyl methacrylate material can be strengthened by adding reinforcing material to the base of the denture plate to increase transverse, impact and tensile strength. ${ }^{2}$

One of the waste materials that can be utilized is fish bone as high-quality organic calcium. Fish bone waste can be processed into hydroxyapatite (HA). HA derived from fish bone waste contains calcium, phosphorus, and carbonate. HA is a calcium phosphate containing hydroxide with the chemical formula $\mathrm{Ca}_{10}\left(\mathrm{PO}_{4}\right)_{6}(\mathrm{OH})_{2}$ which is widely used in medicine and dentistry as artificial bone. HA has an important chemical property that is biocompatible so it does not cause a rejection reaction from the immune system by the human body. ${ }^{3,4}$

Skipjack fish bones (katsuwonus pelamis) are a natural source of HA and have great potential in the future with its $84.22 \%$ high mineral content. ${ }^{4}$ Extraction begins with the drying and grinding of prepared skipjack fish bones. Then immersion is carried out in acetone, then it is roasted and calcined. Hydroxyapatite synthesis is done by adding phosphoric acid solution. While adjusting the $\mathrm{pH}$ is by adding $\mathrm{NaOH}$. The precipitate is then re-dried to get a powder containing HA. ${ }^{5}$

Transverse strength or compressive strength is the load applied to a rod-shaped object supported at both ends and the load is given in the middle, as long as the bar is pressed the load will increase regularly and stop when the test rod is broken. Transverse strength is a combination of compression strength, tensile strength and shear strength. Impact strength is the durability of a material as not to break when it gets a large and sudden power in the form of tension and compression. Impact tests on acrylic resins are used to test resistance to sudden loads that can occur, such as when falling to the floor. Tensile strength is a measure of the 
strength of a material when it receives a load that tends to stretch or extend the material. Tensile strength can be tested by placing a long material, wire, or dumbbell shape on the tensile force (one axis tensile test). This test can be carried out only on material which shows elastic deformation and slight or no plastic deformation. ${ }^{6,7}$

This study was conducted to determine the effect of HA from skipjack fish bones on transverse strength, impact strength and tensile strength of acrylic.

\section{Material and Methods}

This study is a laboratory experimental research post-test-only control group design. The sample of this research is a heat cured acrylic resin in the form of a long plate with a length of $65 \mathrm{~mm}$, a width of $10 \mathrm{~mm}$, and a thickness of $2.5 \mathrm{~mm} .{ }^{8}$ Each test requires 27 samples for 3 treatment groups with each group of 9 samples. Group 1: Heat cured acrylic resin which is added with 0\% HA powder from acrylic resin powder. Group 2: Heat cured acrylic resin which is added with $2 \% \mathrm{HA}$ powder from acrylic resin powder. Group 3: Heat cured acrylic resin which is added 5\% HA powder from acrylic resin powder.

Transverse strength test is carried out using Universal Testing Machine test. Acrylic plates are numbered at both ends and lines in the middle using a pencil and placed in such a way. The instrument will press precisely on one plate line at intervals of 30 seconds until the fracture occurs. The values listed are recorded and entered in the transversal strength formula: ${ }^{7}$

$$
S=\frac{3 \mathrm{IP}}{2 b d^{2}}
$$

Explanations:

$$
\begin{aligned}
& \mathrm{S}=\text { Transverse strength }(\mathrm{N} / \mathrm{mm} 2) \\
& \mathrm{b}=\text { plate width }(\mathrm{mm}) \\
& \mathrm{l}=\text { length } / \text { supporting distance }(\mathrm{mm}) \\
& \mathrm{d}=\text { plate thickness }(\mathrm{mm}) \\
& \mathrm{P}=\operatorname{load}(\mathrm{N})
\end{aligned}
$$

Impact strength is measured by the impact testing machine with the Charphy method. This test is carried out at room temperature. The plate is placed on the anvil, raised to as high as $h$ or at the angle of $\alpha$ (at this measurement the angle of $\alpha$ is taken at $90^{\circ}$ ). Then adjust the position of the needle scale guide to the zero position. The pendulum is released so that it hits the test piece, the pendulum will still swing as high as $h$ or at the $\beta$ angle. Then observed and noted the angle changes that occur. Then the calculation is done with formula. ${ }^{9}$

$$
\mathrm{IS}=\frac{\mathrm{W} \cdot \mathrm{L}(\cos \beta-\cos \alpha)(\mathrm{gram} / \mathrm{cm})}{\mathrm{A}}
$$

Explanations:

$$
\begin{aligned}
\text { IS }= & \text { Impact Strength } \\
\mathrm{W}= & \text { pendulum weight }+ \text { metal weight }(750 \\
& \text { gram }) \\
\mathrm{L}= & \operatorname{arm} \text { length }(332.6 \mathrm{~cm}) \\
\alpha= & \text { the initial angle of the pendulum before } \\
& \text { swinging }(900) \\
\beta= & \text { the angle of the pendulum after swinging } \\
\mathrm{A}= & \text { wide of cross section testing rod }(\mathrm{cm} 2)
\end{aligned}
$$

Tensile strength measurement is done by tensile strength test equipment (Autograph, Japan), the sample is placed vertically with the tip located on a strong grip (grip) on the test instrument then read and recorded the resulting force and then calculate the tensile strength using formula: ${ }^{7}$

$$
\sigma=\frac{F}{A}
$$

Explanations:

$$
\begin{aligned}
& \sigma: \text { voltage } \\
& F: \text { force } \\
& A: \text { cross-sectional area }
\end{aligned}
$$

To statistically test whether there are significant differences in the observations of each variable based on the treatment group (2\% and 5\%) and the control group $(0 \%)$, data were analyzed using the One-way Anova test.

\section{Results}

Skipjack tuna bone that has been calcined then tested with XRF to determine the content of $\mathrm{CaO}$ formed. As a result, there was $68.14 \% \mathrm{CaO}$ in the sample. Then after the precipitation process, XRD characterization test was performed. The results showed that tuna bone powder contained hydroxyapatite as much as $11.3 \%$. Furthermore, based on the results of the FTIR test it can be seen that the $\mathrm{OH}^{-}$group, the $\mathrm{CO}_{3}^{2-}$ group, and the $\mathrm{PO}_{4}^{3-}$ group on several wave numbers $\left(\mathrm{cm}^{-1}\right)$. The $\mathrm{OH}^{-}$group which is shown by the emergence of a peak at wave number 3500-3650 $\mathrm{cm}^{-1}$, the $\mathrm{PO}_{4}^{3-}$ group which is indicated by the emergence of peaks at wave numbers 1000 1100 and $500-600 \mathrm{~cm}^{-1}$, and the $\mathrm{CO}_{3}^{2-}$ group which is indicated by the emergence of the peak at wave number $1400-1500 \mathrm{~cm}^{-1}$.

Based on statistical results figure 1, there was a significant difference in the average transverse strength between groups $(\mathrm{p}<0.05)$. Transverse strength increased slightly in group 2 , then decreased in group 3. 


\section{Transversal strength}

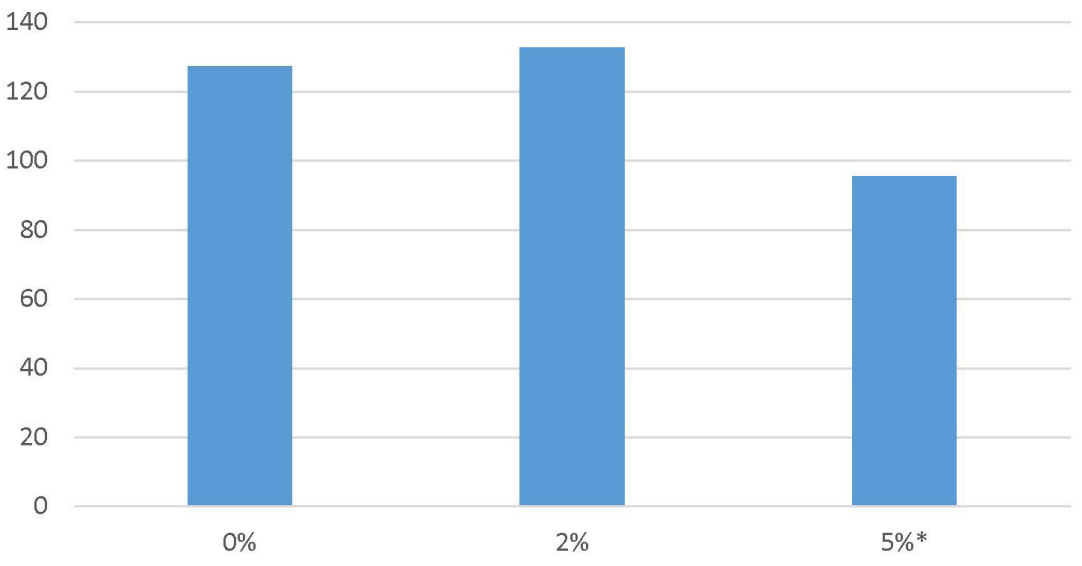

Figure 1 Average transversal strength $\left(\mathrm{N} / \mathrm{mm}^{2}\right)$ in each sample Groups marked with ${ }^{*}$ have a significant difference compared to controls

\section{Impact strength}

0.14

0.12

0.1

0.08

0.06

0.04

0.02

0

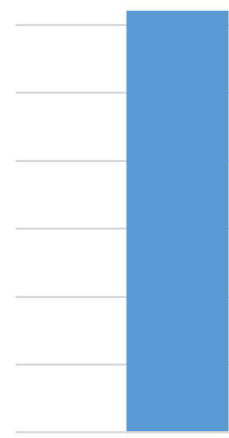

$0 \%$

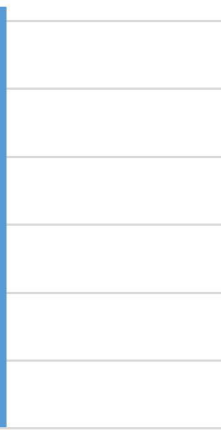

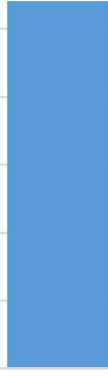

$2 \%$

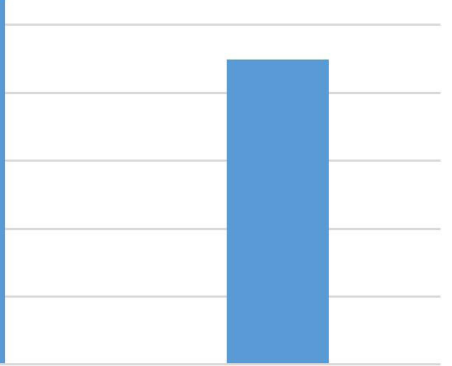

$5 \% *$
Figure 2 Average impact strength $(\mathrm{kg} / \mathrm{cm} 2)$ in each sample Groups marked with ${ }^{*}$ have a significant difference compared to controls

\section{Tensile strength}

60

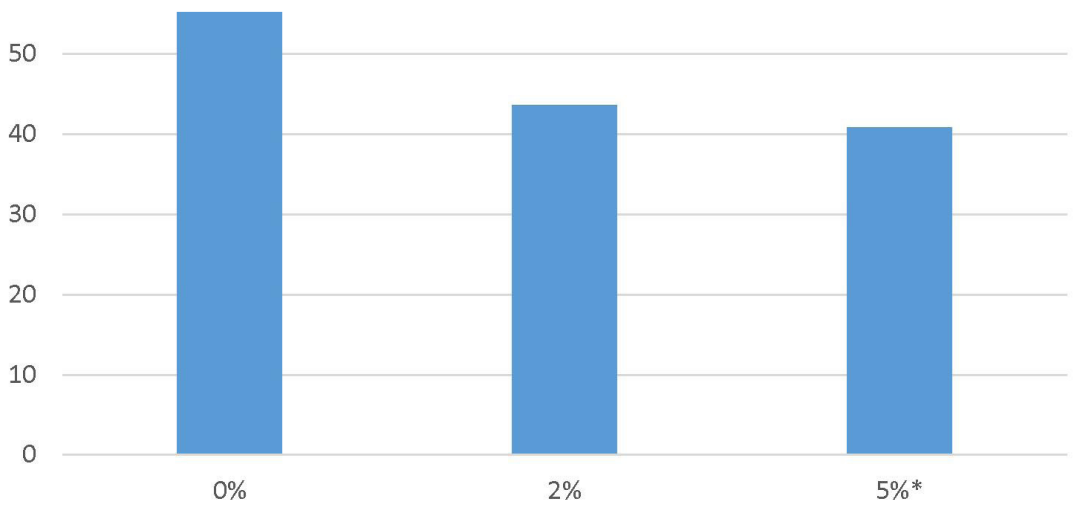

Figure 3 Average tensile strength $(\mathrm{N} / \mathrm{mm} 2)$ in each sample Groups marked with ${ }^{\star}$ have a significant difference compared to controls
Based on statistical results figure 2, there was a significant difference in the average impact strength between groups $(\mathrm{p}<0.05)$. Impact strength decreases with increasing percentage of hydroxyapatite of skipjack fish bones.

Based on statistical results figure 3 , there were significant differences between groups $(\mathrm{p}<0.05)$. Tensile strength decreases with increasing percentage of hydroxyapatite added.

\section{Discussion}

The strength of heat cured acrylic resin is influenced by the composition of its constituent materials. The strength of acrylic is caused by the good bond between the monomer and the polymer. The more filler added will reduce the relative amount of the polymer matrix, reduce contraction pressure, and decrease the amount of liquid absorption. As a result, the bonds formed will be lower. ${ }^{10}$

Increased transverse strength in groups with the addition of $2 \%$ hydroxyapatite can occur due to the formation of bonds between hydroxyapatite and polymer chains. The bond will help distribute the pressure evenly received to all parts of the material so that the acrylic resin's ability to withstand changes in shape and increase its transverse strength. This is similar to the addition of fiber to increase the transverse strength of acrylic resins. The addition of volumetric fibers will result in more pressure absorption and the forces that appear can be transmitted to the entire surface of the matrix properly. ${ }^{11}$

Meanwhile in the group with the addition of $5 \%$ hydroxyapatite, there was a decrease in the amount of more polymer. Acrylic is more susceptible to plasticization because of the presence of non-polymerized monomers. This is what causes a decrease in transverse strength. Low polymer monomer bonding can also reduce the ability to distribute pressure on the acrylic resin matrix, causing a decrease in transverse strength. Adding fiber does not always increasing transverse strength. ${ }^{10}$

The weak matrix bonding between the polymer and hydroxyapatite also causes a decrease in impact strength in the two treatment groups by adding $2 \%$ and $5 \%$ hydroxyapatite. This is similar to the research conducted by Chow et al on the mechanical and thermal properties of hydroxyapatite-filled polymethyl methacrylate composites. It is said that the flexural strength of PMMA is reduced by the incorporation of hydroxyapatite. This may occur due to agglomeration of HA particles in the PMMA matrix. In addition, the reduction in strength can also be associated with a mismatch between PMMA and HA, as well as the presence of interfacial matrix-particle defects. ${ }^{12}$ 
The impact strength of heat cured acrylic resins can be influenced by several factors such as crazing, water absorption, and residual monomers. The occurrence of these three factors is influenced by the formation of polymer chains that occur during the polymerization process (boiling). ${ }^{7}$ At a high percentage of hydroxyapatite addition, the amount of polymer powder will be reduced more because it is replaced by hydroxyapatite powder while the number of monomers does not change. Although the percentages of $2 \%$ and $5 \%$ of hydroxyapatite added to acrylic resins produce a homogeneous mixture and without chemical reactions, monomers that are not bound to polymers will produce weaker bonds or become residual monomers and affect the mechanical properties of acrylic resins. ${ }^{13}$

The tensile strength of acrylic is influenced by the temperature of the polymerization. Changes in high ambient temperature cause shrinkage of acrylic resin particles. The lack of bond between acrylic and hydroxyapatite because of the inhomogeneity of the two materials causes the shrinkage of acrylic resin particles to be greater than hydroxyapatite particles. This will reduce the tensile strength as happened in this study. ${ }^{14}$

The weakness in this study is the value of the transverse strength in each sample tested in one group shows mixed results. Factors that might make this diversity is the treatment of samples that are less consistent because it is done repeatedly and manually. As an example, polishing samples might reduce the thickness of the acrylic sample. In addition, the results of the XRD characterization test showed that the hydroxyapatite content formed in skipjack tuna bone flour was still quite low. The presence of other ingredients contained in skipjack tuna bone flour may affect the bond that occurs between the polymer and its HA. ${ }^{15}$

\section{Conclusion}

Hydroxyapatite made from skipjack tuna fish bone flour affects the mechanical strength of acrylic resin, such as transverse, impact and tensile strength. Increasing the hydroxyapatite percentage will further reduce its strength because it decreases the bonds formed between the monomer and the polymer.

\section{Acknowledgment}

This work was supported by Faculty of Dentistry, Brawijaya University.

\section{Conflict of Interest}

The authors report no conflict of interest.

\section{References}

1. Abdullah ZS. The effect of addition of hydroxyapatite microscopic fillers on surface roughness and some mechanical properties of heat cured acrylic resin. J Baghdad Coll Dent 2015;27: 50-54.

2. Gad MM, Fouda SM, Al-Harbi FA, et al. PMMA denture base material enhancement: A review of fiber, filler, and nanofiller addition. Int $\mathrm{J}$ Nanomedicine 2017;12: 3801-3812.

3. Cahyanto A, Kosasih E, Aripin D, et al. Fabrication of hydroxyapatite from fish bones waste using reflux method. IOP Conf Ser Mater Sci Eng 2017;172: 012006.

4. Riyanto B, Maddu A. Material of hydroxyapatite-based bioceramics from tuna fishbone. J Pengolah Has Perikan Indones 2014;16: 119-132.

5. Mutmainnah M, Chadijah S, Rustiah WO. Hidroksiapatit dari tulang ikan tuna sirip kuning (tunnus albacores) dengan metode presipitasi. Al-Kimia 2017;5: 119-126.

6. Anusavice K, Shen C, Rawls HR. Phillips' science of dental materials. 12th ed. US: Saunders; 2012. p. 48-68.

7. Sakaguchi R, Ferracane J, Powers J. Craig's restorative dental materials. 14th ed. US: Mosby; 2018. p. 29-48.

8. American Dental Association. Revised American Dental Association specification no. 12 for denture base polymers. J Am Dent Assoc 1975;90: 451-458.

9. Setyohadi R, Nugrahini D, Ummah LLAm El. The effect of siwak solution as cleansing in heat cured acrylic submersion to impact strength. E-Prodenta J Dent 2017;1: 15-22.

10. Leitune VCB, Collares FM, Trommer RM, et al. The addition of nanostructured hydroxyapatite to an experimental adhesive resin. J Dent 2013;41: 321-327.

11. Ellakwa AE, Shortall AC, Marquis PM. Influence of fiber type and wetting agent on the flexural properties of an indirect fiber reinforced composite. J Prosthet Dent 2002;88: 485-490.

12. Chow WS, Tay HK, Azlan A, et al. Mechanical and thermal properties of hydroxyapatite filled poly ( methyl methacrylate ) composites. Proc Polym Process Soc 24th Annu Meet 2008: 1-3.

13. Hassan ZJ, Hatim NA, Taqa AA. Study the FTIR of hydroxyapatite addi- tive to heat cured acrylic resin. Al Rafidain Dent J 2014;14: 32-36.

14. Zebarjad SM, Sajjadi SA, Sdrabadi TE, et al. A study on mechanical properties of pmma/hydroxyapatite nanocomposite. Engineering 2011;3: 795-801.

15. Maghfiroh H, Nugroho R, Probosari N. The effect of carbonated beverage to the discoloration of polished and unpolished nanohybrid composite resin. J Dentomaxillofac Sci 2016;1: 16-19.

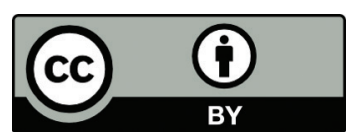

This work is licensed under a Creative Commons Attribution 